\title{
ПРИНЦИПЫ И УСЛОВИЯ ПЛАНИРОВАНИЯ РАССЛЕДОВАНИЯ ПЕНИТЕНЦИАРНЫХ ПРЕСТУПЛЕНИЙ
}

\author{
Н. В. Жарко \\ Академии ФСИН России
}

Поступила в редакцию 4 февраля 2021 г.

\begin{abstract}
Аннотация: исследуются руководящие начала планирования расследования пенитенииарных преступлений. Приниипь и условия планирования расслатриваются как единая систела общих требований, правил, которыли в обязательнол порядке руководствуются органы предварительного расследования в иелях успешного раскрытия и расследования пенитенииарного преступления.
\end{abstract}

Ключевые слова: приниипь планирования, условия планирования, план расследования, следственные версии, следственнье ситуации, расследование пенитенциарных преступлений.

\begin{abstract}
: this article examines the guidelines for planning the investigation of penitentiary crimes. The principles and conditions of planning are considered as a single system of general requirements, rules that must be followed by the preliminary investigation bodies in order to successfully solve and investigate a penitentiary crime.
\end{abstract}

Key words: planning principles, planning conditions, investigation plan, investigative versions, investigative situations, investigation of penitentiary crimes.

Успех при выполнении лицом, производящим расследование пенитенциарного преступления, своих обязанностей в соответствии с законодательством, как правило, зависит от грамотного и четкого планирования $^{1}$, в основе которого лежит исчерпывающая отработка различных версий следствия как главное условие нахождения истины. О том, что основной причиной ошибок и недоработок в деятельности следственных органов является отсутствие четкого плана расследования преступлений, специалисты указывали еще несколько десятилетий назад, впрочем, и в наше время такие обстоятельства встречаются нередко. Одним из объяснений тому выступает слабая теоретическая подготовленность следственного аппарата, исключающая научно-теоретический пласт знаний о планировании и версионном процессе расследования пенитенциарных преступлений. $К$ другим аргументам некачественного расследования следует отнести психологическую составляющую некоторых следователей, а именно их самонадеянность, привычка обходиться в своей работе набросками, напоминающими план-конспект на день. Многие молодые сотрудники, прибывшие на службу, не имея достаточного следственного

${ }^{1}$ См.: Данилова И. Ю., Жарко Н. В., Новикова Л. В. Планирование как необходимая составляющая расследования пенитенциарного преступления // Евразийский юрид. журнал. 2020. № 10 (149). С. 230.

(C) Жарко Н. В., 2021 
опыта, не всегда умеют и могут составить развернутый письменный план расследования пенитенциарного преступления.

Кроме того, в любом правовом институте существует ряд принципов, которыми следует руководствоваться для получения эффективных результатов в том или ином виде деятельности. Институт планирования расследования пенитенциарных преступлений не является исключением: принципы планирования их расследования представляют собой установленные общие требования, правила, которыми в обязательном порядке руководствуются органы предварительного расследования.

Вместе с тем вопросы, касающиеся принципов планирования расследования, вызывают споры среди ученых-криминалистов до настоящего времени. Так, исследовав труды Р. С. Белкина, А. Н. Васильева, А. М. Ларина, Н. А. Лузгина, мы пришли к следующему заключению: единого мнения по данной проблеме ученые не выработали. В связи с этим представляется целесообразным подробнее рассмотреть понятие «принципы планирования», необходимое их число и содержание.

Принципы планирования расследования пенитенциарного преступления можно разделить на две категории: 1) безусловно принимаемые, в отношении которых нет критики и сомнений (это принципы законности, обоснованности, полноты, научности, соответствия фрормы и содержания) ${ }^{2}$; 2) специфические принципы (индивидуальности, конкретности, системности, своевременности и динамичности).

Суть принципа законности планирования расследования пенитенциарных преступлений состоит в неукоснительном исполнении лицом, производящим расследование, законов и соответствующих им нормативных правовых актов ${ }^{3}$.

Принцип обоснованности планирования расследования преступлений означает объективное, аргументированное исследование обстоятельств дела. Вследствие этого деятельность лица, производящего расследование, по составлению и написанию плана расследования пенитенциарного преступления должна основываться на конкретных данных. При формулировании версий и определении задач расследования конкретного преступления необходимо учитывать достоверные фракты и производить оценку имеющейся информации.

Принцип полноты планирования расследования пенитенциарных преступлений целесообразно рассматривать как принцип целостности, тщательности, внутреннего единства, непротиворечивости при определении последовательности версий и вида действий лица, производящего расследование. Так, составляемый план расследования пенитенциарно-

${ }^{2}$ См.: Кузьлин С. В. Принципы планирования расследования // Известия вузов. Правоведение. 2018. № 2. С. 132.

${ }^{3}$ См.: Гришин Д. А. Нарушение принципа законности при производстве расследования : правовые и неправовые последствия // Актуальные проблемы юридической науки и практики : взгляд молодых ученых : материалы VIII науч.-практ. конф. молодых ученых Академии Генеральной прокуратуры Рос. Федерации. М., 2016. C. 250-257. 


\section{Вестник ВГУ. Серия: Право}

го преступления должен обозначать программу данного процесса, которая будет влиять на эфрфективность и реализуемость поставленных задач как при обозначении версий, так и при решении вопросов по производству отдельных следственных действий.

Принцип научности планирования расследования пенитенциарных преступлений следует относить в планировании к стадии познания, которая призывает учитывать рекомендации, выработанные криминалистической наукой по применению сил, средств, приемов в поиске, сохранении и использовании доказательной базы ${ }^{4}$. Кроме того, данный принцип предоставляет возможность использовать достижения науки для эфррективного применения технических средств, рабочего времени, взаимодействия с различными участниками уголовного процесса, правильной организации труда, для наиболее структурированного и эфрекктивного использования своих возможностей при расследовании пенитенциарного преступления.

Принцип соответствия формы и содержания планирования расследования пенитенциарных преступлений - это процесс отражения мыслительной деятельности следователя в письменных планах расследования и всевозможных приложениях к нему (схемах, таблицах, графиках, зарисовках и т. д.).

Общеизвестно, что письменный план играет основополагающую роль в планировании расследования пенитенциарного преступления, позволяет лицу, производящему расследование, эффективно его организовать, представить наглядно ход расследования и постоянно вести контроль собственных действий, что поможет анализировать увеличивающийся поток информации по делу. Подобным образом составленный план демонстрирует четко изложенную стратегию расследования и его перспективы, а значит, дает возможность избежать спешки - частой причины ошибок, недоработок, пробелов и др. ${ }^{5}$

К сожалению, практики чаще всего пренебрегают очевидной необходимостью составления письменного плана расследования, объясняя это чрезмерной загруженностью, нехваткой времени, а иногда и попросту незнанием и неумением его составлять.

Представляется целесообразным рассмотреть специфические принципы, сущность которых в научной литературе трактуется неоднозначно, к ним отнесем принципы индивидуальности, конкретности, системности, своевременности и динамичности.

Не секрет, что расследование любого преступления имеет определенные особенности, свою исключительность, требует индивидуального подхода, тем более если речь идет о пенитенциарном преступлении. Так, в

${ }^{4}$ См.: Белкин Р. С. Курс криминалистики // Частные криминалистические теории : в 2 т. М., 2017. Т. 2. С. 199.

${ }^{5}$ См.: Акчурин A. B. Состояние и перспективные направления криминалистических исследований проблем расследования пенитенциарных преступлений // Пенитенциарная система и общество : опыт взаимодействия : материалы VI Междунар. науч.-практ. конф. М., 2019. С. 185-188. 
соответствии с принципом индивидуальности планирования раскрытия пенитенциарных преступлений лицо, производящее расследование, при составлении плана расследования должно учесть все нюансы, особенности, специфрику по каждому уголовному делу, находящемуся у него в производстве. Индивидуальность предполагает недопустимость шаблона, а также учет конкретной следственной ситуации, не присущей расследованию другого пенитенциарного преступления.

Тем не менее принцип индивидуальности не исключает рекомендаций, указаний, непосредственного направления хода деятельности относительно расследования пенитенциарного преступления по исходным данным и однотипным ситуациям, вне зависимости от вида того или иного преступления. Именно поэтому мы можем говорить о типичном планировании по уголовным делам одной и той же категории исключительно по отношению к начальной стадии расследования ${ }^{6}$.

В начале расследования преступлений, совершаемых на территории исправительных учреждений, некоторые следственные действия необходимо спланировать и провести как можно быстрее, так как со стороны осужденных возможны попытки преднамеренного уничтожения следов преступления ${ }^{7}$. Например, при совершении побега осужденным путем преодоления охранных сооружений необходимо привлечь к осмотру места происшествия ${ }^{8}$ сотрудников отдела охраны, провести осмотр места побега, произвести обыск подозреваемого, его места проживания, осмотр изъятых у него запрещенных предметов. Такой алгоритм следственных действий характерен для любого конкретного дела: побега, причинения вреда здоровью и т. д. При этом типовой план выступает своего рода фундаментальной частью индивидуально взятого составления плана расследования по уголовному делу, в результате чего он наполняется определенным, свойственным только ему содержанием, обусловленным особенностями того или иного расследуемого преступления.

На наш взгляд, эта позиция хотя и подвергается критике, но имеет право на существование. Некая индивидуальность, определенное своеобразие «типичных планов» не оказывают глобального влияния на расследование конкретного уголовного дела, а служат своего рода подспорьем для отдельно взятого плана по уголовному делу, который наполняется индивидуальными особенностями и конкретными составляющими. Представляется, что некоторые шаблоны по однотипным категориям уго-

${ }^{6}$ См.: Жарко Н. В., Назаркин Е. В., Новикова Л. В. Планирование и выдвижение версий на первоначальном этапе расследования преступлений // Евразийский юрид. журнал. 2019. № 1 (128). С. 302-304.

${ }^{7}$ См.: Новикова Л. В., Жарко Н. В. Тактические и методические приемы обнаружения следов при осмотре места происшествия // Евразийский юрид. журнал. 2016. № 9 (100). C. 244-245.

${ }^{8}$ См.: Жарко Н. В., Данилова И. Ю., Новикова Л. В. Проблемы проведения осмотра места происшествия в исправительном учреждении // Пенитенциарная система и общество : опыт взаимодействия : материалы VI Междунар. науч.-практ. конфр. М., 2019. С. 204-206. 
ловных дел целесообразно закрепить в локальных нормативных правовых актах в качестве рекомендаций, указаний, алгоритмов деятельности.

Принцип конкретности планирования расследования пенитенциарных преступлений своими характерными чертами перекликается с принципом индивидуальности, однако существенные отличия у них есть. Сущность данного принципа определяется тем, что в плане расследования пенитенциарного преступления не должно быть декларативности, т. е. общих, расплывчатых формулировок. Основные составляющие плана должны быть четко обозначены, конкретизированы, лаконично сформулированы для того, чтобы работа лица, производящего расследование, была максимально понятна для успешного ее выполнения. Все обстоятельства, которые подлежат установлению по выдвинутым версиям, действия и мероприятия, необходимые для выполнения в период расследования, с точным указанием конкретных исполнителей, места проведения и сроков вносятся в план расследования пенитенциарных преступлений. $\mathrm{K}$ конкретизации планирования необходимо стремиться настолько, насколько это необходимо и возможно, и тогда план расследования пенитенциарного преступления станет не только направляющим началом, но и действующим инструментом эфффективной деятельности лица, производящего расследование.

Принцип системности планирования расследования пенитенциарных преступлений представляет процесс планирования как упорядоченную, внутренне согласованную систему. Каждый элемент плана является или может стать отдельной, автономной системой, но в то же время представлять собой составную часть общей системы. Системность планирования - это четкая взаимосвязь намеченных в плане действий и мероприятий, взаимодействие исполнителей ${ }^{9}$, всеобщее стремление к достижению поставленных целей и выполнению задач, неукоснительная и постепенная реализация всех пунктов плана расследования пенитенциарного преступления.

Принцип своевременности планирования расследования преступлений определяет выполнение намеченных планом пунктов в наиболее оптимальные сроки. Своевременное обозначение конкретных задач, планирование отдельных следственных действий, организация намеченных

260 мероприятий помогают достичь поставленной цели - раскрыть пенитенциарное преступление. Так, сотрудники исправительного учреждения, опоздав с производством осмотра, обыска на его территории, могут не получить ценные для следствия сведения, не обнаружить следы преступления и вещественные доказательства, а значит, свести на нет шансы следствия раскрыть преступление в ближайшее время ${ }^{10}$.

${ }^{9}$ См.: Гришин Д. А. Взаимодействие при расследовании преступлений // Актуальные проблемы уголовного права, криминологии, уголовного процесса и уголовно-исполнительного права : теория и практика : материалы VI Междунар. науч.-практ. конфр. Рязань, 2017. С. 82-87.

${ }^{10}$ См.: Антипов В. П. Планирование расследования нераскрытых преступлений. М., 2002. С. 33. 
Не все криминалисты признают справедливость существования данного принципа, считая, что правильнее всего будет составить план расследования пенитенциарного преступления лишь после того, как будут произведены первоначальные следственные действия и собрана информация, проливающая свет на совершение данного деяния. По нашему мнению, такое утверждение не совсем справедливо, ведь сотрудники следственных органов перед выездом на место происшествия уже имеют определенную информацию, с помощью которой уже на этом этапе можно начать строить свою работу по определенному плану ${ }^{11}$ (например, как добраться до места производства следственного действия, каких специалистов надо привлечь, какие технико-криминалистические средства понадобятся и т. д.).

Принцип динамичности показывает: планирование нельзя считать разовым актом, который остается в ходе расследования уголовного дела стабильным и не подвержен изменениям. Меняется сама следственная ситуация, поступают новые сведения, находятся новые следы, даются показания свидетелей, потерпевших и иных лиц. Всё это не может не влиять на составленный план расследования, поэтому план должен дополняться и изменяться, новые версии рассматриваться и утверждаться либо отклоняться. Таким образом, планирование должно отличаться оперативностью и непрерывностью. Именно динамические поправки в плане расследования с оценкой его точности и доработки позволят лицу, производящему расследование пенитенциарных преступлений, добиться максимальных результатов.

Завершая рассмотрение представленных принципов планирования расследования пенитенциарных преступлений, можно сделать вывод: они тесно взаимосвязаны и составляют все вместе единый слаженно работающий механизм. Одни принципы дополняют другие, тем самым определяя наиболее важные аспекты планирования. Правильное руководство исследованными принципами и условиями планирования позволит лицу, производящему расследование, достичь конечного результата успешного раскрытия и расследования пенитенциарного преступления.

\section{Библиографический список}

Акчурин А. В. Состояние и перспективные направления криминалистических исследований проблем расследования пенитенциарных преступлений // Пенитенциарная система и общество : опыт взаимодействия : материалы VI Междунар. науч.-практ. конфр. Рязань, 2019. С. 185-188.

Антипов В. П. Планирование расследования нераскрытых преступлений. М. : Юрлитинформ, 2002. 144 с.

Бабаева Э. У. Проблемы теории и практики преодоления противодействия уголовному преследованию. М., 2006. 312 с.

Белкин Р. С. Курс криминалистики : в 2 т. М., 2017. Т. 2 : Частные криминалистические теории. $464 \mathrm{c}$.

${ }^{11}$ См.: Бабаева Э. У. Проблемы теории и практики преодоления противодействия уголовному преследованию. М., 2006. С. 29. 
Гришин Д. А. Взаимодействие при расследовании преступлений // Актуальные проблемы уголовного права, криминологии, уголовного процесса и уголовно-исполнительного права : теория и практика : материалы VI Междунар. науч.-практ. конф. Рязань, 2017. С. 82-87.

Гришин Д. А. Нарушение принципа законности при производстве расследования : правовые и неправовые последствия // Актуальные проблемы юридической науки и практики : взгляд молодых ученых : материалы VIII науч.-практ. конф. молодых ученых Академии Генеральной прокуратуры Российской Федерации. М., 2016. С. 250-257.

Данилова И. Ю., Жарко Н. В., Новикова Л. В. Планирование как необходимая составляющая расследования пенитенциарного преступления // Евразийский юрид. журнал. 2020. № 10 (149). С. 228- 230.

Жарко Н. В., Данилова И. Ю., Новикова Л. В. Проблемы проведения осмотра места происшествия в исправительном учреждении // Пенитенциарная система и общество : опыт взаимодействия : материалы VI Междунар. науч.-практ. конф. М., 2019. С. 204-206.

Жарко Н. В., Назаркин Е. В., Новикова Л. В. Планирование и выдвижение версий на первоначальном этапе расследования преступлений // Евразийский юрид. журнал. 2019. № 1 (128). С. 302-304.

Кузьлин С. В. Принципы планирования расследования // Известия вузов. Правоведение. 2018. № 2. С. 132.

Новикова Л. В., Жарко Н. В. Тактические и методические приемы обнаружения следов при осмотре места происшествия // Евразийский юрид. журнал. 2016. № 9 (100). С. 244-245.

\section{References}

Akchurin A. V. State and perspective directions of criminalistic research of problems of investigation of penitentiary crimes. Penitentiary system and society: experience of interaction: collection of materials. VI International Scientific and Practical Conferences. Ryazan, 2019. P. 185-188.

Antipov V. P. Planning the investigation of unsolved crimes. M. : Yurlitinform, 2002. $144 \mathrm{p}$.

Babayev E. W. The theory and practice of overcoming a counter criminal prosecution: monograph. M. : Yurlitinform, 2006. 312 p.

Belkin R. S. Kurs criminalistiki. Kn. 2: Private criminalisticheskie teoriiv.

262 M., 2017. 464 p.

Grishin D. A. Interaction in the investigation of crimes. Actual problems of criminal law, criminology, criminal procedure and criminal executive law: theory and practice: mater. VI mezhdunar. nauch.-pract. Conf. Ryazan, 2017. P. 82-87.

Grishin D. A. Violation of the principle of legality during the investigation: legal and non-legal consequences // Actual problems of legal science and practice: the view of young scientists: sat. mater. VIII Scientific and practical Conference of Young scientists of the Academy of the General Prosecutor's Office of the Russian Federation. M., 2016. P. 250-257.

Danilova I. Yu., Zharko N. V., Novikova L. V. Planning as a necessary component of the investigation of a penitentiary crime // Eurasian Legal Journal. 2020. № 10 (149). P. 228-230. 
Zharko N. V., Danilova I. Yu., Novikova L. V. Problems of conducting an inspection of the scene of an accident in a correctional institution. Penitentiary system and society: experience of interaction: collection of materials. VI International Scientific and Practical Conference. M., 2019. P. 204-206.

Zharko N. V., Nazarkin E. V., Novikova L. V. Planning and development of versions at the initial stage of crime investigation // Eurasian Legal Journal. 2019. № 1 (128). P. 302-304.

Kuzmin S. V. Principles of investigation planning // Izvestiya vuzov. Jurisprudence. 2018. № $2.132 \mathrm{p}$.

Novikova L. V., Zharko N. V. Tactical and methodological techniques for detecting traces when examining the scene of an accident // Eurasian Legal Journal. 2016. № 9 (100). P. 244-245.

\section{Для иитирования:}

Жарко Н. В. Принципы и условия планирования расследования пенитенциарных преступлений // Вестник Воронежского государственного университета. Серия: Право. 2021. № 3 (46). С. 256-263. DOI: https://doi.org/10.17308/vsu.proc.law.2021.3/3555

\section{Recommended citation:}

Zharko $N$. $V$. The principles and conditions for planning the investigation of penitentiary crimes // Proceedings of Voronezh State University. Series: Law. 2021. № 3 (46). P. 256-263. DOI: https://doi.org/10.17308/vsu.proc.law.2021.3/3555

\section{Академии ФСИН России}

Жарко Н. В., кандидат юридических наук, доцент кафбедрь уголовного проиесса и крилиналистики

E-mail:nwm2011@yandex.ru
Academy of Law and Management of the FPS of Russia

Zharko N. V., Candidate of Legal Sciences, Associate Professor of the Criminal Process and Criminalistics Department

E-mail: nwm2011@yandex.ru 